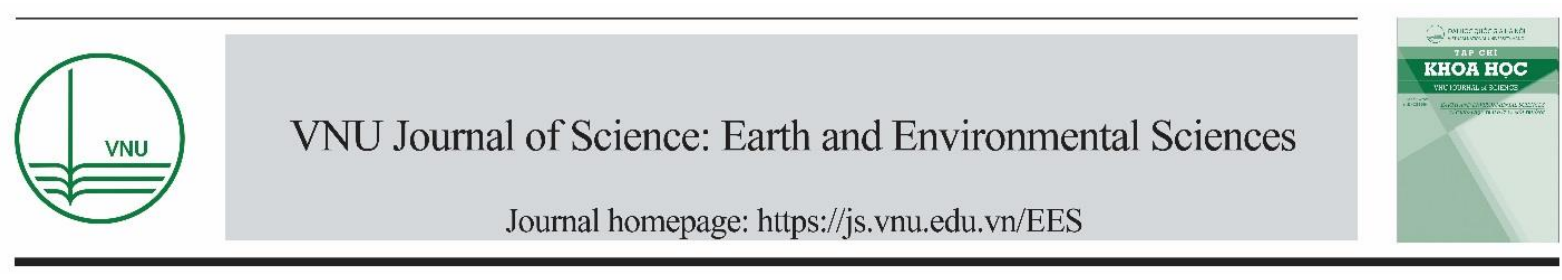

Original Article

\title{
Determination of Shoreline Changes along Upstream of Se San River, Kontum Province based Multi-temporal Remote Sensing Data Analysis
}

\author{
Pham Thu Thuy ${ }^{1, *}$, Pham Viet $\mathrm{Hoa}^{2}$, Vu Van Tich ${ }^{1}$, Pham Minh Tam ${ }^{3}$ \\ ${ }^{1}$ Science and Technology Department, Vietnam National University, Hanoi, 144 Xuan Thuy, Hanoi, Vietnam \\ ${ }^{2}$ Ho Chi Minh City Institute of Resources Geography, 01 Mac Dinh Chi, Ho Chi Minh city, Vietnam \\ ${ }^{3}$ Faculty of Geography, VNU University of Science, 334 Nguyen Trai, Ha Noi, Vietnam
}

Received 01 September 2020

Revised 25 September 2020; Accepted 01 October 2020

\begin{abstract}
Se San river upstream includes Poko tributary (on the right bank) and Dak Bla tributary (on the left bank), mostly located in Kon Tum province. The process of river sediment decline has dramatic shoreline changes in this area, which becomes a driving-force to modify the current socioeconomic development as well as the impact on territorial planning in the future. This study aims to analyze the shoreline changes by extracting multi-temporal satellite imagery of Landsat in the period of 1990-2013 and identify its change effects on land-use. The results show that the strongest erosion rate was $-2.96 \mathrm{~m} / \mathrm{year}$ in Dak Bla tributary (in Kon Tum town). And in the Poko tributary, the average value of erosion rate is $-1.31 \mathrm{~m} /$ year and the average accretion rate is $1.17 \mathrm{~m} /$ year. In the context of dramatic land-use change, this approach allows to support for territorial management and illustrates the accretion-erosion relationship in river basin evolution.
\end{abstract}

Keywords: Se San river basin, shoreline change, multi-temporal remote sensing data.

\footnotetext{
* Corresponding author.

E-mail address: phamthuthuy@vnu.edu.vn
}

https://doi.org/10.25073/2588-1094/vnuees.4673 


\title{
Nghiên cứu xác định biến động đường bờ thượng lưu sông Sê San, tỉnh Kontum trên cơ sở phân tích dữ liệu viễn thám đa thời gian
}

\author{
Phạm Thu Thủy ${ }^{1, *}$, Phạm Việt Hòa², Vũ Văn Tích ${ }^{1}$, Phạm Minh Tâm³ \\ ${ }^{1}$ Ban Khoa học Công nghệ, Đại học Quốc gia Hà Nội, 144 Xuân Thủy, Hà Nội, Việt Nam \\ ${ }^{2}$ Viện Địa lý tài nguyên thành phố Hồ Chí Minh, 01 Mạc Đĩnh Chi, Hồ Chí Minh, Việt Nam \\ ${ }^{3}$ Khoa Địa lý, Truò̀ng Đại học Khoa học Tự nhiên, ĐHQGHN, 334 Nguyễn Trãi, Hà Nội, Việt Nam
}

Nhận ngày 01 tháng 09 năm 2020

Chỉnh sửa ngày 25 tháng 9 năm 2020; Chấp nhận đăng ngày 01 tháng 10 năm 2020

\begin{abstract}
Tóm tắt: Thượng lưu sông Sê San bao gồm chi lưu Pô Kô (phía hữu ngạn) và Đăk Bla (phía tả ngạn) nằm hầu hết trên địa phận tỉnh Kon Tum. Quá trình suy giảm trầm tích sông đã hình thành những biến động đường bờ tại khu vực này, trở thành động lực làm thay đổi hiện trạng phát triển kinh tế xã hội cũng như tác động tới quy hoạch lãnh thổ trong tương lai. Nghiên cứu sử dụng ảnh Landsat trong giai đoạn 1990-2013 để xác định những đường bờ cơ sở nhằm phân tích những thay đổi theo không gian và thời gian; đồng thời, nghiên cứu những ảnh hưởng tới hoạt động sử dụng đất. Kết quả đã chỉ ra rằng điểm sạt lở mạnh nhất nằm trên chi lưu Đăc Bla thuộc địa phận thị xã Kon Tum với tốc độ trung bình 2,96 m/năm. Đối với chi lưu Pô Kô, tốc độ sạt lở trung bình là 1,31 $\mathrm{m} /$ năm và tốc độ bồi tụ trung bình là $1,17 \mathrm{~m} /$ năm. Đặt trong bối cảnh biến động sử dụng đất, cách tiếp cận ước tính biến động này cho phép hỗ trợ đắc lực tới công tác quản lý lãnh thổ và làm sáng tỏ sự tiến hóa lưu vực sông thông qua mối quan hệ giữa bồi tụ-xói lở.
\end{abstract}

Tù khóa: lưu vực sông Sê San, biến động đường bờ, dữ liệu viễn thám đa thời gian

\section{Mở đầu}

Đường bờ và quá trình biến động của nó là một đối tượng nghiên cứu của địa lý học, mô tả sự chuyển đổi qua lại của đất liền-dòng chảy thông qua nguyên nhân của sóng, gió, dòng chảy ven bờ và tác động nhân sinh [1]. Những thay đổi của đường bờ đã và đang tác động tới 45-60\% cư dân toàn cầu, đặc biệt tại lưu vực các con sông lớn có mức độ tập trung dân cư với mật độ cao [2]. Điều này xuất phát từ đặc trưng biến đổi phức tạp của lòng sông, sự thiếu ồn định về cường độ, thay đổi liên tục cả trong ngắn hạn và dài hạn $[3,4]$. Những thay đổi về đường bờ đóng vai trò quan trọng trong "cấu trúc hóa" môi trường xung quanh cũng như gây ra tổn thất trên các khía cạnh kinh tế-xã hội và môi trường cho cộng đồng [5]. Nhu cầu phát hiện, quan trắc và phân tích những thay đổi của lòng sông là nhiệm vụ quan trọng trong giám sát môi trường, hỗ trợ công tác quản lý lãnh thổ và quy hoạch có liên quan tới lưu vực sông [6]. Đặc biệt, tại các dòng chảy sông suối, các nghiên cứu đường bờ ít được chú ý tới do ưu tiên về hệ sinh thái ven sông $[7,8]$, khan hiếm thông tin dữ liệu bởi sự tốn kém chi phí hoặc sự cản trở của địa hình [9], hay những đòi hỏi tính chi tiết cao của từng đoạn đường bờ [10].

\footnotetext{
* Tác giả liên hệ.

Địa chi email: phamthuthuy@vnu.edu.vn

https://doi.org/10.25073/2588-1094/vnuees.4673
} 
Phần lớn các nghiên cứu về biến đổi đường bờ được thực hiện trên cơ sở dữ liệu bản đồ, lập hồ sơ thực địa, khảo sát bằng ảnh hàng không hay LIDAR [11]; tuy nhiên, những kỹ thuật này gặp khó khăn về phạm vi quan trắc [12], thời gian không đảm bảo cho các đánh giá xu hướng dài hạn hay những thay đổi theo mùa $[13,14]$. Đối với các dữ liệu vệ tinh quang học, sự kết hợp của đặc trưng độ phân giải không gian ở mức trung bình với phạm vi bao phủ không gian lớn, và thời gian quan trắc lặp đi lặp lại thường xuyên cho phép khai thác các thông tin tại các địa điểm khó khăn trong đo đạc $[15,16]$. Sự phát triển của hệ thống thông tin ảnh vệ tinh trong vài thập niên qua đã cải thiện các thông số của dữ liệu miễn phí, đặc biệt là ảnh Landsat [17].

Ngoài ra, với sự phát triển của GIS, những hạn chế trong xác định đường bờ và biến động của nó theo thời gian và không gian được khắc phục $[18,19]$. Các kết quả chiết tách thông tin từ công nghệ viễn thám có thể sử dụng trong môi trường GIS như là một giải pháp xây dựng cơ sở dữ liệu và phân tích biến động hiệu quả [20], đóng vai trò quan trọng trong việc hồं trợ ra quyêt định nhanh trên phạm vi rộng với giá thành thấp so với các phương pháp truyền thống [21]. Tại Việt Nam, một số ứng dụng theo hướng tiếp cận GIS trong theo dõi biến động đường bờ đa thời gian bắt đầu được ứng dụng rộng rãi $[22,23]$. Đồng thời, công cụ phân tích định lượng đường bờ dạng số DSAS (Digital Shoreline Analysis System) cho phép: i) xác định tác động đa chiều giữa tự nhiên và vị trí đường bờ được định lượng thông qua xem xét các quá trình bồi tụ hoặc xói lở đường bờ [24]; nhận diện vị trí đường bờ, trên cơ sở đó ước tính những biến động trong quá khứ và dự báo xu thế biến động trong tương lai [25]. Trên cơ sở đó, các kết quả phân tích biến động đường bờ là cơ sở để xác định những khu vực dễ bị tổn thương, phục vụ công tác quy hoạch và quản lý hiệu quả không gian, lãnh thổ ven sông, ven biển.

Tại các quốc gia đang phát triển, khu vực đường bờ trong các lưu vực sông là những nơi “dễ bị tổn thương" dưới tác động của tự nhiên và hoạt động phát triển kinh tế-xã hội [26,27]. Đặc biệt tại thượng lưu sông Sê San (gồm chi lưu Pô Kô và Đăk Bla) phần lớn nằm trên địa bàn tỉnh
Kom Tum-nơi có địa hình núi xen kẹp các thung lũng hẹp với lòng sông cổ và bãi bồi, những biến đổi của đường bờ không chỉ làm thay đổi cảnh quan tự nhiên của lãnh thổ mà còn chi phối hoạt động sản xuất của cư dân ven bờ. Các hiện tượng thời tiết cực đoan, cùng với hoạt động xây dựng hệ thống hồ thủy điện đã và đang thay đổi phạm vi, quy mô và cường độ biến đồi lòng sông của khu vực. Do đó, mục tiêu nghiên cứu hướng tới xác định mức độ biến đổi đường bờ trong quá khứ làm căn cứ đánh giá ảnh hưởng lên các lớp phủ sử dụng đất, phục vụ định hướng giảm thiểu rủi ro thiên tai và thiệt hại tác động đển hoạt động phát triển kinh tế-xã hội ven sông Sê San.

\section{2. Đối tượng, dữ liệu và phương pháp nghiên cứu}

\section{1. Đối tương nghiên cứu}

Khu vực nghiên cứu được lựa chọn là Sông Sê San-một nhánh lớn của sông Mekong bắt nguồn từ Bắc và Trung Tây Nguyên của Việt Nam, sông chảy sang lãnh thổ Campuchia và nhập vào hệ thống sông Serepok. Thượng lưu sông Sê San gồm chi lưu Pô Kô (tả ngạn) bắt nguồn từ dãy núi Ngọc Krinh và Đăk Bla (hữu ngạn) chảy từ phía Nam của khối núi Ngọc Linh, và chi lưu Đăk Bla có đầu nguồn nằm ở độ cao $1.650 \mathrm{~m}$, chảy từ khu vực có địa hình đồi núi hẹp với động lực dòng lớn. Thượng lưu sông Đăk Bla tương đối thẳng, trong lòng hẹp, dòng chảy theo hướng từ Bắc xuống Nam, có chiều dài khoảng $74 \mathrm{~km}$ và độ dốc $1,7 \%$. Sông Pô Kô chạy trong thung lũng hẹp dạng hình chữ $\mathrm{V}$ với độ dốc khoảng 3,3\%, dài khoảng $21 \mathrm{~km}$. Sự khác biệt trong điều kiện địa hình và đặc điểm dòng chảy của hai chi lưu khiến quá trình đánh giá biến động đường bờ dưới tác động của tự nhiên trở nên phức tạp. Mặt khác, hoạt động khai thác tài nguyên và xây dựng hệ thống hồ thủy điện trên lưu vực sông đã và đang làm thay đổi mức độ và tốc độ bồi tụ, sạt lở của hai bên bờ sông. Điều này dẫn tới những khó khăn trong quá trình định hình đường cơ sở và tính toán những thay đổi của quá trình xói lở-bồi tụ của lòng dẫn. Trong nghiên cứu, lòng sông được nhận định là đường nằm trong giới hạn đường bờ nước tại thời điểm chụp ảnh (có thể phân biệt giữa ranh giới đấtnước hay nước và thực vật). 

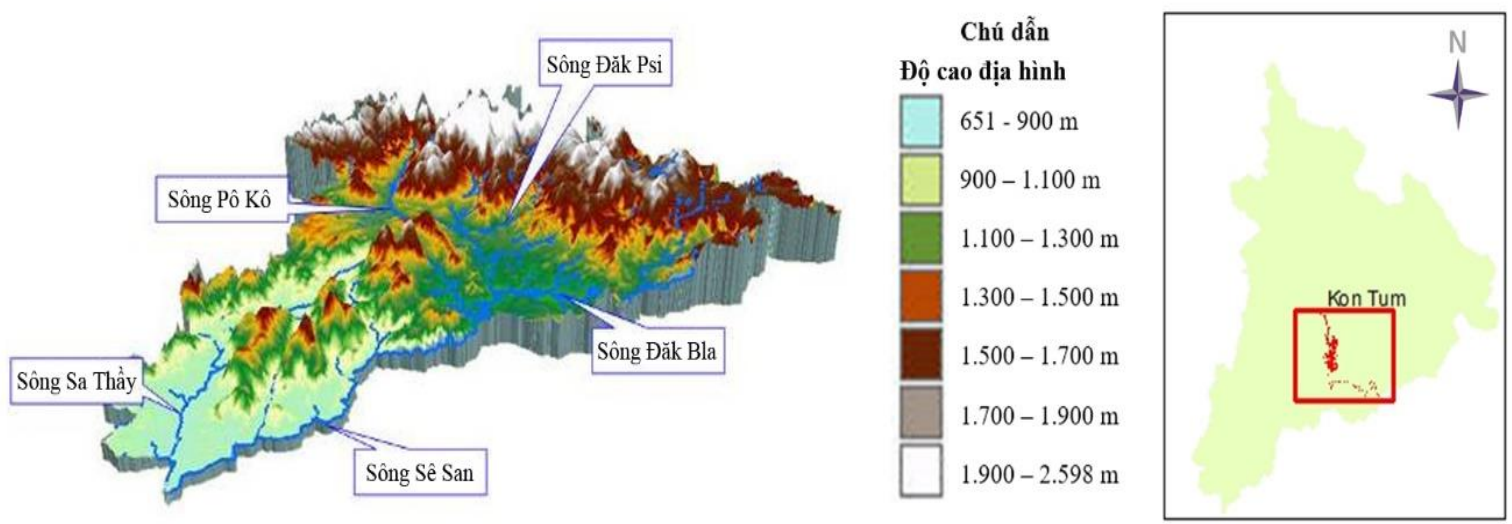

Hình 1. Sơ đồ vị trí khu vực nghiên cứu.

\subsection{Dũ liệu và phương pháp nghiên cứu}

Sơ đồ tiến trình nghiên cứu được biểu diễn cụ thể trong Hình 2, gồm các bước thực hiện thu thập dữ liệu, giải đoán ảnh viễn thám và phân tích biến động đường bờ. Các dữ liệu viễn thám đa thời gian (ảnh Landsat 5, Landsat 7 vào các năm 1990, 2002 và 2013) được tải miễn phí trên trang web https://earthexplorer.usgs.gov/. Dũ liệu ảnh vệ tinh được thu nhận vào mùa khô (từ tháng 12 đến tháng 3): (i) ảnh Landsat 5 TM chụp vào ngày 30/12/1990; (ii) ảnh Landsat 7 ETM+ chụp vào ngày 22/02/2002; và (iii) ảnh Landsat 7 ETM+ chụp vào ngày 03/01/2013

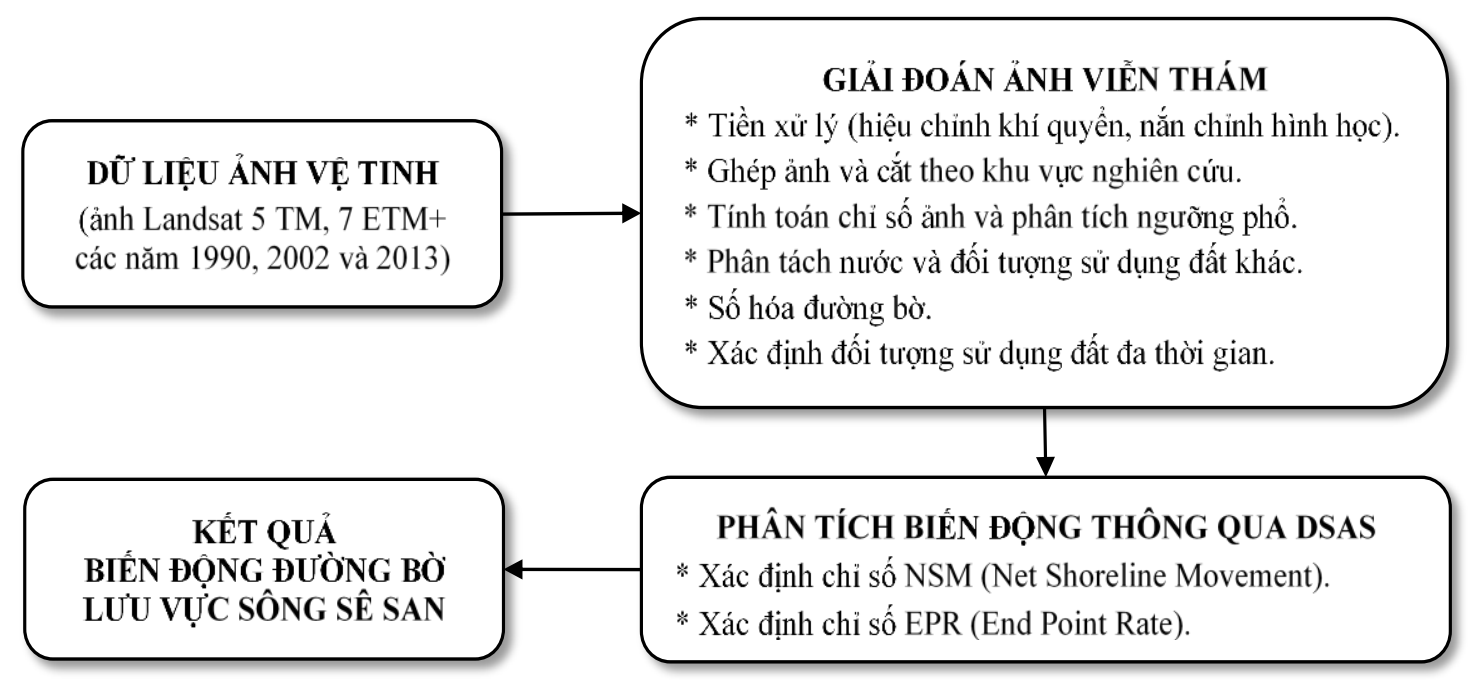

Hình 2. Sơ đồ tiến trình nghiên cứu.

a. Giải đoán ảnh viễn thám đa thời gian

Một số đặc trưng ảnh viễn thám Landsat 5 và Landsat 7 được tóm tắt trong Bảng 1 . Dũ liệu viễn thám đa thời gian được hiệu chỉnh khí quyển và nắn chỉnh hình học ở mức $2 \mathrm{~A}$. Cơ sở dữ liệu được đưa về cùng hệ quy chiếu WGS-84 UTM, múi $49 \mathrm{~N}$ với sai số về độ chính xác nhỏ hơn 0,5 pixel. 
Bảng 1. Đặc trưng ảnh viễn thám Landsat 5 (TM) và Landsat 7 (ETM+)

\begin{tabular}{|c|l|c|c|c|c|}
\hline Stt & \multicolumn{1}{|c|}{ Tên band ảnh } & Bước sóng & Độ phân giải (m) & Kênh LS 5 & Kênh LS 7 \\
\hline 1 & Lam (Blue) & $0.45-0.52$ & 30 & 1 & 1 \\
\hline 2 & Lục (Green) & $0.52-0.60$ & 30 & 2 & 2 \\
\hline 3 & Đỏ (Red) & $0.63-0.69$ & 30 & 3 & 3 \\
\hline 4 & Cận hồng ngoại (Near IR) & $0.76-0.90$ & 30 & 4 & 4 \\
\hline 5 & Hồng ngoại sóng ngắn (SWIR) & $1.55-1.75$ & 30 & 5 & 5 \\
\hline 6 & Hồng ngoại nhiệt (Thermal IR) & $10.40-12.50$ & $120(\mathrm{TM}) / 60(\mathrm{ETM}+)$ & 6 & 6 \\
\hline 7 & Hồng ngoại sóng ngắn (SWIR) & $2.08-2.35$ & 30 & 7 & 7 \\
\hline 8 & Đơn sắc (Panchromatic) & $0.52-0.90$ & 15 & & 8 \\
\hline
\end{tabular}

Dữ liệu ảnh vệ tinh Landsat 7 (Scan Line Corrector (SLC)-off) thu được sau ngày 31/05/2003 đều gặp phải lỗi sọc ảnh. Nghiên cứu tiến hành hiệu chỉnh bằng các dữ liệu có thời gian chụp lân cận thông qua công cụ Gap-Fill

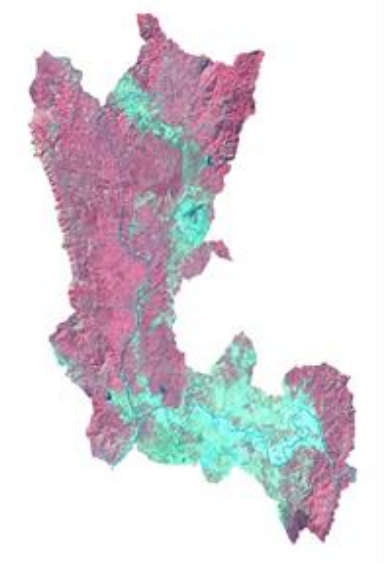

Năm 1990

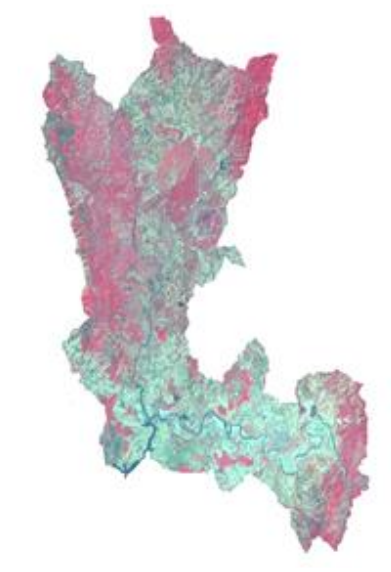

Năm 2002 trên phần mềm ENVI 4.8. Trước khi thực hiện giải đoán ảnh, dữ liệu nghiên cứu được cắt theo ranh giới chung nhằm tăng tốc độ xử lý. Dữ liệu đầu vào được biểu diễn trong Hình 3 .

Hình 3. Dữ liệu viễn thám giai đoạn 1990-2013 sau quá trình tiền xử lý ảnh.

* Giải đoán ảnh nhằm xác định ranh giới đường bờ: Do độ phân giải của ảnh Landsat ở mức trung bình $(30 \mathrm{~m})$, nghiên cứu tiến hành quy ước phần mép nước thu được là đường bờ của dòng chảy. Quá trình chiết tách thông tin được thực hiện trên cơ sở đặc trưng phổ của mặt nước trên kênh hồng ngoại và cận hồng ngoại của ảnh Landsat bị hấp thụ mạnh; trong khi đối tượng đất và thực vật thì ngược lại - hấp thụ ít và phản xạ nhiều hơn [28]. Thông qua chỉ số của Winasor và S. Budhiman (2001) [29], công thức ảnh tỷ số [(Band 5 + Band 7) / Band 2] được áp dụng nhằm khai thác lợi thế của Band 5 tương phản mạnh về ranh giới giữa đất và nước do hâp thụ mạnh năng lượng hồng ngoại của nước (thậm chí cả với nước đục) và phản xạ mạnh hồng ngoại của thảm thực vật. Giá trị phổ của mặt nước có sự tập trung cao $(95 \%$ các giá trị phổ trong khoảng $[0,3 ; 6]$ với độ lệch chuẩn là 0,8727 ). Từ đó, phương pháp phân ngưỡng cho kênh ảnh tỉ số nhằm tạo các lát cắt giá trị (density slice) giúp tối ưu hóa miền giá trị phổ của đối tượng mặt nước (giá trị nằm trong khoảng $[0,17 ; 0,96])$. Dữ liệu sau xử lý ở định dạng raster được chuyển đổi sang dạng vector dưới sự hỗ trợ của phần mềm ArcGIS 10.4. Tiến trình xử lý được tóm tắt trong Hình 4. 


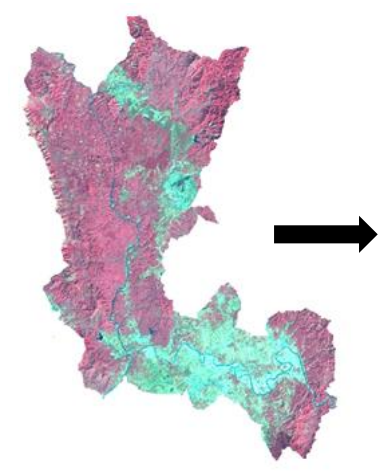

Änh tổ hợp màu

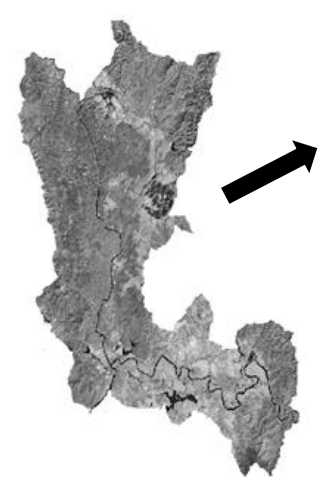

Änh chỉ số $[(\mathrm{B5}+\mathrm{B} 7) / \mathrm{B} 2]$

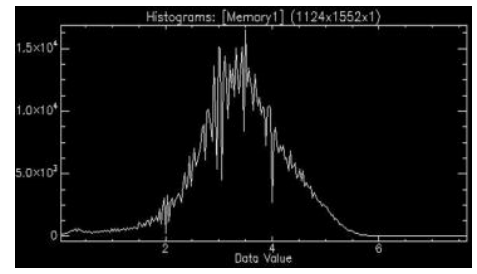

Phương pháp Density Slide

Chiết tách ranh giới đường bò

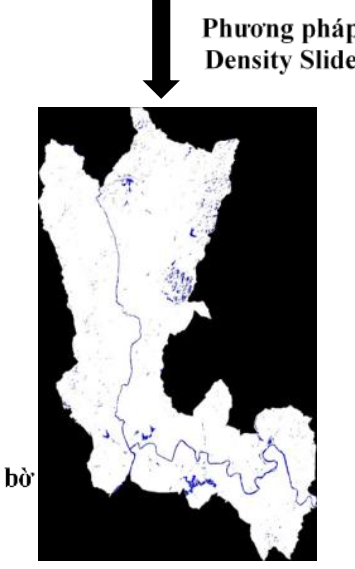

Hình 4. Khái quát tiến trình chiết tách đối tượng mặt nước trên ảnh Landsat trên cơ sở ảnh chỉ số.

* Giải đoán ảnh nhằm xác định hiện trạng sủ dụng đất: Quá trình trích xuất các đặc trưng đối tượng địa lý là bước quan trọng nhất của hoạt động phân loại ảnh, nhằm khai thác các đặc điểm quan trọng của đối tượng ở quy mô nhỏ cho mục đích phân loại tổng thể. Trong nghiên cứu này, thuật toán phân loại không điểm định K-means được sử dụng trong giải quyết vấn đề phân cụm thông qua các bước: i) đặt một số lượng cụm nhất định (giả sử $\mathrm{k}$ cụm) là tiên nghiệm cố định trong không gian; ii) những điểm này đại diện cho trọng tâm các nhóm ban đầu; iii) gán từng đối tượng cho nhóm có tâm gần nhất; iv) khi tất cả đối tượng được gán thuộc tính, tiến hành tính toán lại vị trí của trọng tâm $\mathrm{k}$; v) lặp lại tiến trình tới khi trọng tâm không còn di chuyển nhằm tối thiểu hóa số lượng cụm dữ liệu. Và thuật toán giảm thiểu hàm mục tiêu (objective function) này được xác định bằng công thức của MacQueen (1967) [30]:

$$
J=\sum_{j=1}^{k} \sum_{i=1}^{n}\left\|x_{i}^{(j)}-c_{j}\right\|^{2}
$$

Trong đó, $\left\|x_{i}^{(j)}-c_{j}\right\|^{2}$ là khoảng cách tính toán được chọn giữa các điểm dữ liệu $x_{i}^{(j)}$ và các trung tâm cụm $c_{j}$; là một chỉ báo về khoảng cách của $n$ điểm dữ liệu từ các trung tâm cụm tương ứng của chúng. Nghiên cứu tiến hành phân loại 06 đối tượng sử dụng đất (gồm có: lòng sông, bãi bồi, đất nông nghiệp, cây công nghiệp, rừng và đất trống) dưới sự trợ giúp của phần mềm ENVI 4.8.

b. Phân tích biến động đường bờ thông qua công cu DSAS

Quá trình phân tích biến động đường bờ được xác định thông qua tính toán diễn biến xói lở và bồi tụ bờ sông. Cơ sở khoa học của phương pháp này là xây dựng các đường cắt ngang (transect) vuông góc cắt tất cả các đường bờ (river bank) theo các khoảng cách được lựa chọn (transect spacing) từ một đường cơ sở (baseline). Dưới sự trợ giúp của phần mềm DSAS (Digital Shoreline Analysis System) và Hệ thống thông tin địa lý (GIS), tốc độ biến động đường bờ (End Point Rate) được xác định bằng tỷ số giữa 
khoảng cách thay đổi của đường bờ và đường co sở (tính bằng $\mathrm{m}$ ) với khoảng thay đổi giữa hai thời đoạn (tính bằng năm) [31]:

$$
E P R=\frac{D_{1}-D_{2}}{t_{1}-t_{0}}
$$

Trong đó, $\mathrm{D}_{1}$ và $\mathrm{D}_{2}$ : khoảng cách giữa đường bờ và đường cơ sở tại hai thời điểm; $\mathrm{t}_{0}$ và $\mathrm{t}_{1}$ : thời điểm của hai vị trí biến đổi đường bờ.

Mức độ biến đổi của đường bờ (Net Shoreline Movement) được xác định trên cơ sở công thức sau [31]:

$$
N S M=D_{t 2}-D_{t 1}
$$

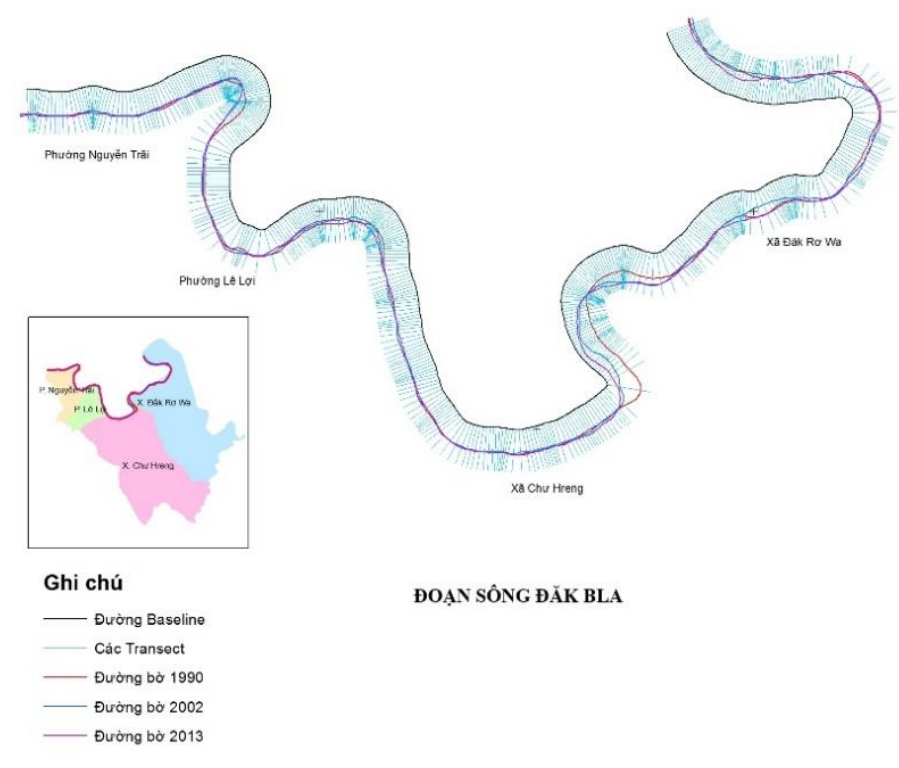

Trong đó, $\mathrm{D}_{\mathrm{t} 1}$ và $\mathrm{D}_{\mathrm{t} 2}$ là khoảng cách đường bờ năm sớm nhất và gần nhất cho mỗi mặt cắt trên đường cơ sở.

Cách tiếp cận này cho phép phân tích định lượng những biến đổi trong không gian của đường bờ tại khu vực nghiên cứu. Lựa chọn đường bờ năm 1990 làm đường gốc, đường baseline được xây dựng trên cơ sở tạo vùng đệm từ đường gốc và cách đều đường gốc $200 \mathrm{~m}$. Với mỗi khoảng cách đều $30 \mathrm{~m}$, nghiên cứu tiến hành xây dựng 516 transect cho đoạn sông Đăk Bla và 217 transect cho đoạn sông Pô Kô. Lưới các transect chi tiết được mô tả trong Hình 5.

Hình 5. Sơ đồ xây dựng lưới transect cho hai đoạn lưu vực sông Sê San dưới sự trợ giúp của phần mềm DSAS.

\section{Kết quả nghiên cứu}

3.1. Đánh giá biến động đường bò̀ khu vục nghiên cúu giai đoạn 1990-2013 trên cơ sở công cu DSAS

Trên cơ sở cách tiếp cận của Thieler et al. (2009), nghiên cứu tiến hành tính toán bồi tụ và sạt lở giai đoạn 1990-2013 cho phần đường bò sông Đăk Bla nơi chảy qua 4 phường/xã gồm: phường Nguyễn Trãi, phường Lê Lợi, xã Chư
Hreng và xã Đăk Rơ Wa (từ đây gọi tắt là đoạn sông Đăk Bla): (i) phường Nguyễn Trãi: các transect có số thứ tự từ 1 tới 137; (ii) phường Lê Lợi: các transect số thứ tự từ 138 tới 248; (iii) xã Chư Hreng: các transect có số thứ tự từ 249 tới 298; (iv) xã Đăk Rơ Wa: các transect số thứ tự từ 299 tới 516. Mức độ và tốc độ biến động của đường bờ tại chi lưu Đăk Bla giai đoạn này được biểu diễn trong Hình 6 . 

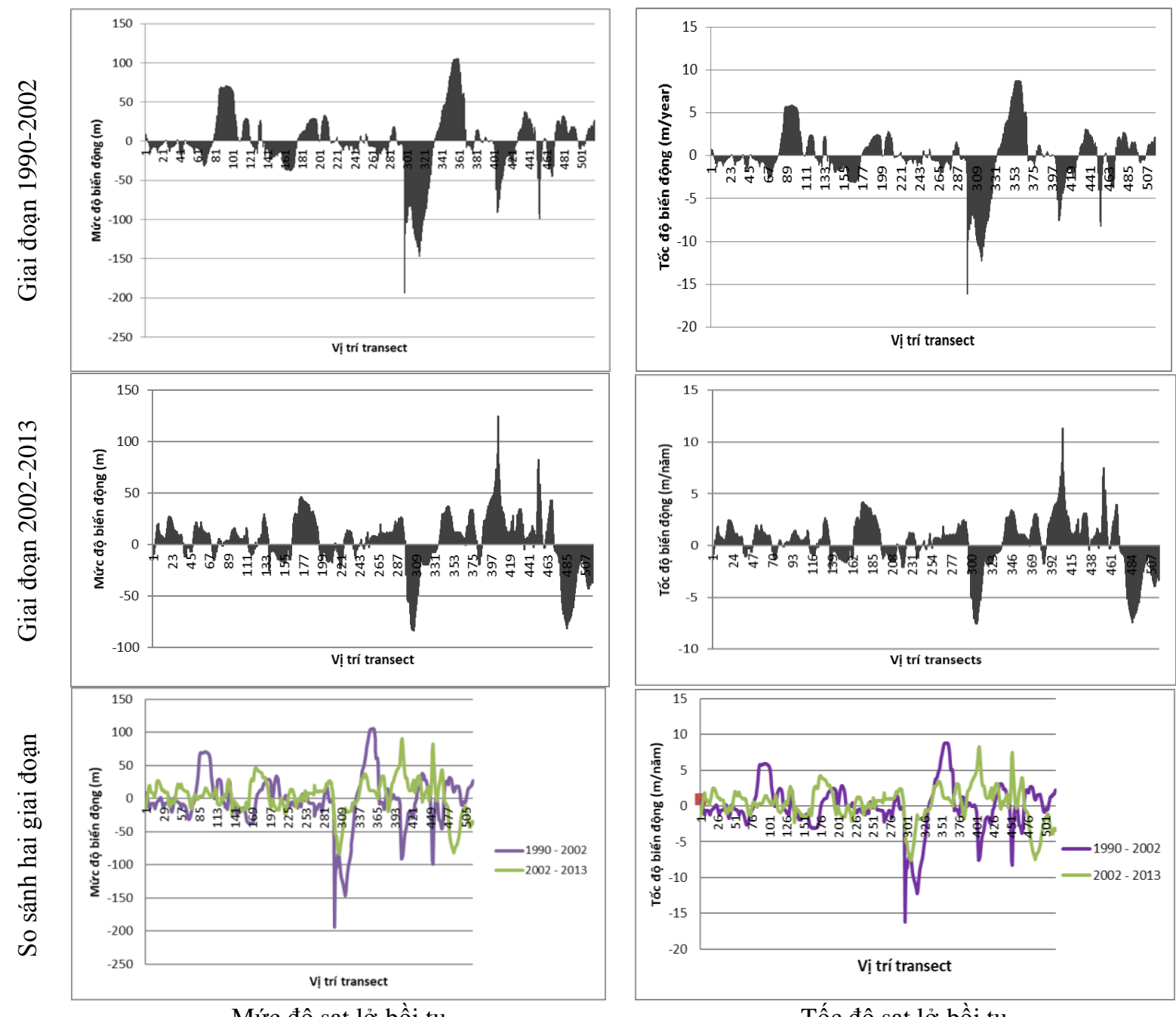

Tốc độ sạt lở-bồi tụ

Hình 6. Thống kê mức độ và tốc độ sạt lở-bồi tụ tại chi lưu Đăk Bla giai đoạn 1990-2013 (>0 lở, <0 bồi).

Theo đó, trong giai đoạn 12 năm (19902002), 221/516 transect ghi nhận hiện tượng sạt lở, 295/516 transect ghi nhận quá trình bồi tụ, và không có transect nào không biến đổi. Hiện tượng sạt lở xảy ra biến thiên từ $-0,19 \mathrm{~m}$ đến $105,51 \mathrm{~m}$, tốc độ duy trì từ $-0,015 \mathrm{~m} /$ năm đến $8,79 \mathrm{~m} /$ năm với giá trị trung bình 12 năm ước đạt -2,34 m/năm; tập trung chủ yếu ở phần giữa khúc sông chảy qua xã Đăk Rơ Wa và phường Nguyễn Trãi. Quá trình bồi tụ xảy ra biến thiên từ $+0,01$ $\mathrm{m}$ đến $+194,14 \mathrm{~m}$, tốc độ duy trì từ $+0,008$ $\mathrm{m} /$ năm đến $+16,17 \mathrm{~m} /$ năm với giá trị trung bình 12 năm ước đạt $+2,07 \mathrm{~m} / \mathrm{năm}$; tập trung chủ yếu ở khu vực khúc sông giáp ranh giữa xã Chư Hreng và xã Đăk Rơ Wa.

Trong giai đoạn 11 năm (2002-2013), có 321/516 transect ghi nhận hiện tượng sạt lở, có 195/516 transect ghi nhận quá trình bồi tụ, và không có transect nào không biến đổi. Hiện tượng sạt lở xảy ra biến thiên từ - $0,09 \mathrm{~m}$ đến $11,34 \mathrm{~m}$, tốc độ duy trì từ $-0,01 \mathrm{~m} / \mathrm{năm}$ đến $11,34 \mathrm{~m} / \mathrm{năm}$ với giá trị trung bình 11 năm ước đạt $-2,96 \mathrm{~m} / \mathrm{năm}$; tập trung chủ yếu phường Lê Lợi và khúc giữa sông chảy qua xã Đăk Rơ Wa. Quá trình bồi tụ xảy ra biến thiên từ $+0,06 \mathrm{~m}$ đến $+83,6 \mathrm{~m}$, tốc độ duy trì từ $+0,1 \mathrm{~m} /$ năm đến 
$+10,45 \mathrm{~m} /$ năm với giá trị trung bình 11 năm ước đạt $+2,23 \mathrm{~m} / \mathrm{năm}$; tập trung chủ yếu ở khu vực khúc sông giáp ranh giữa xã Chư Hreng và xã Đăk Rơ Wa và khúc sông giáp ranh giữa xã Đăk Rơ Wa và xã Đăk Blà (lên tới mức $+10,45 \mathrm{~m}$ ).

Từ kết quả thống kê biến động đường bờ đoạn sông Đăk Bla trong hai giai đoạn, xu hướng sạt lở gia tăng về cả về mức độ và tốc độ (từ 221 transect trong giai đoạn 1990-2002 lên 321 transect giai đoạn 2002-2013; tốc độ sạt lở trong khoảng $[-0,015 ;-8,79]$ giai đoạn 1990-2002 thay đổi thành $[-0,01 ;-11,34]$ giai đoạn 2002-2013;

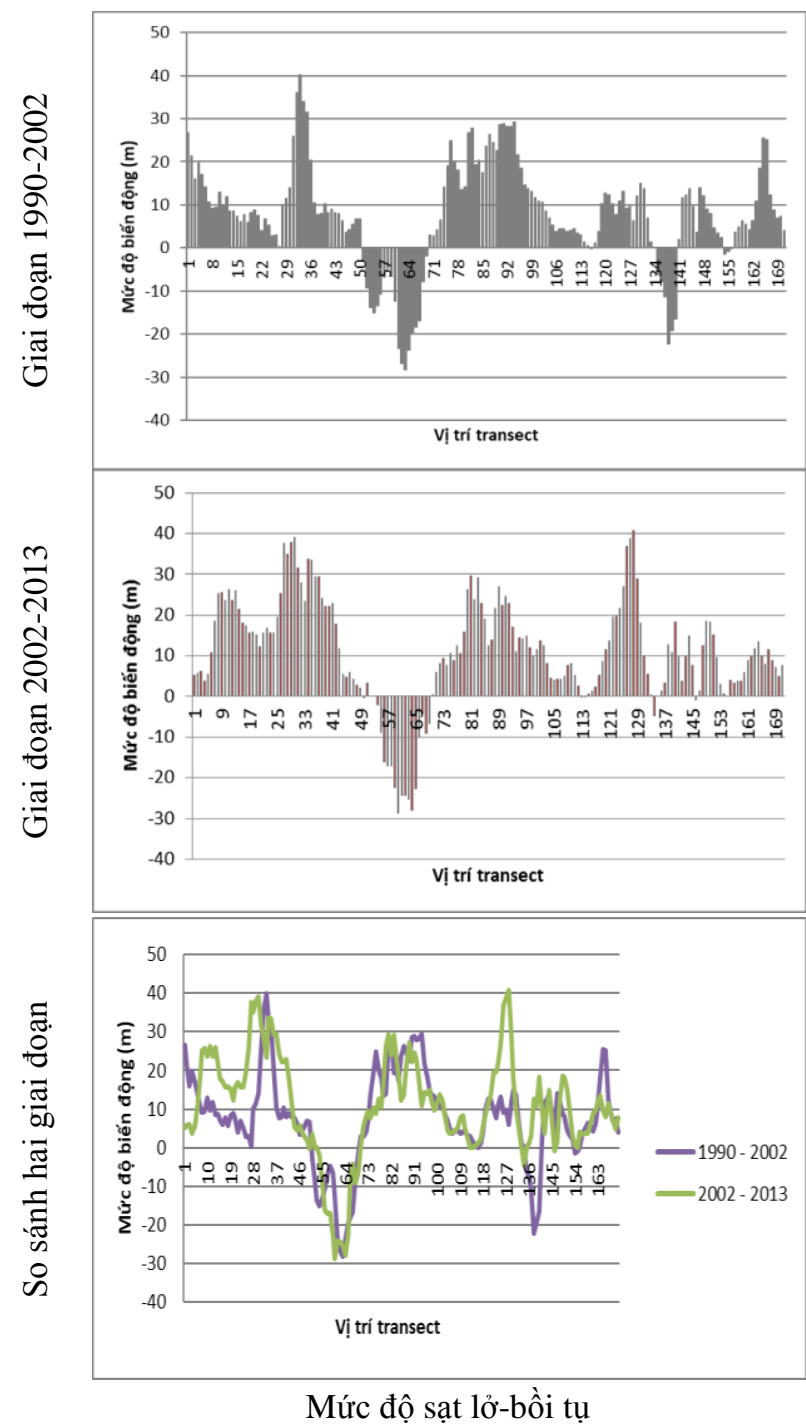

tốc độ sạt lở trung bình toàn khu vực thay đổi từ $-2,34$ đến $-2,96 \mathrm{~m} / \mathrm{năm})$. Trong khi đó, xu hướng bồi tụ giảm dần cả về mức độ và tốc độ.

Nghiên cứu cũng tiến hành tính toán bồi tụ và sạt lở giai đoạn 1990-2013 cho phần đường bờ sông Pô Kô chảy qua xã Kroong, nằm giao với sông Sê San và Đăk Bla, với chiều dài đoạn bờ sông khoảng $5,3 \mathrm{~km}$ (theo bờ trái hướng thủy văn). Tổng số 217 transect được tạo ra và lựa chọn đánh số lần lượt từ theo hướng từ dưới lên trên.
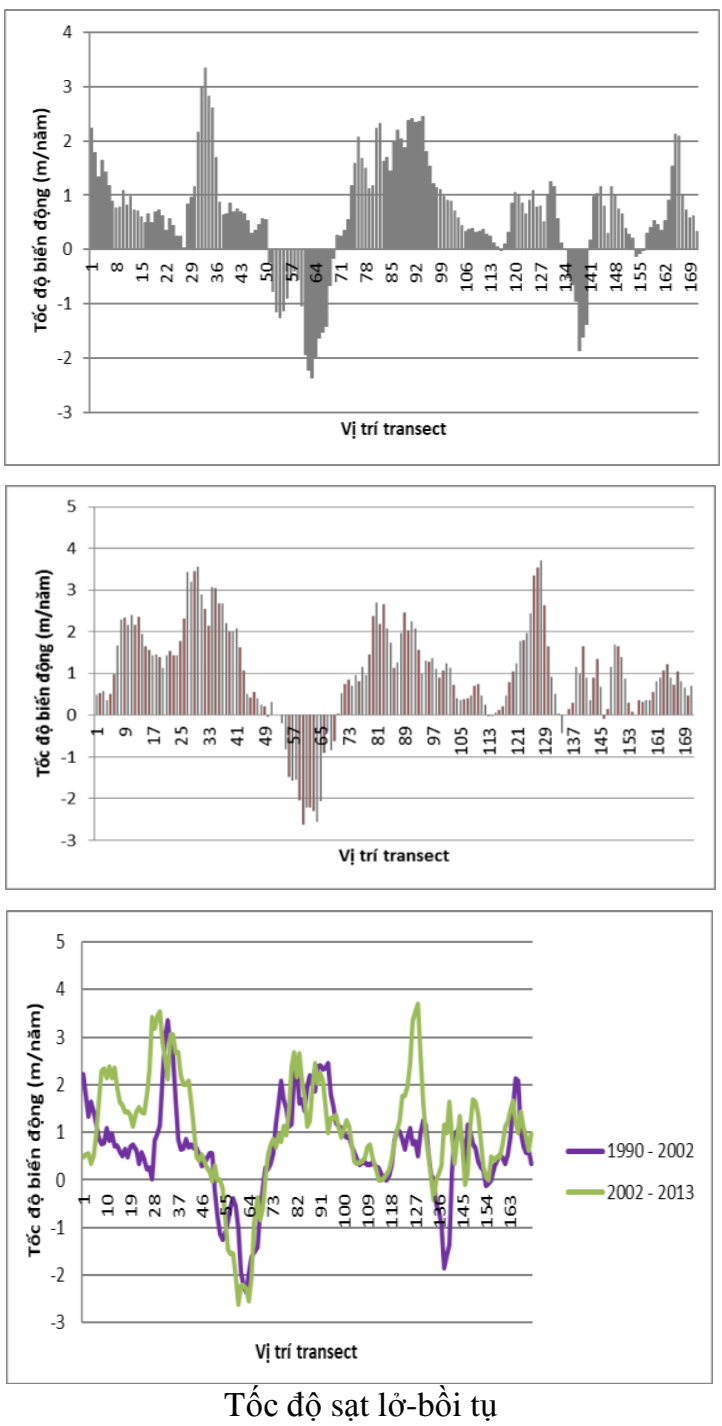

Hình 7. Thống kê mức độ và tốc độ sạt lở-bồi tụ tại chi lưu Pô Kô giai đoạn 1990-2013 (>0 lở, <0 bồi). 
Theo đó, trong giai đoạn 12 năm (19902002), có 141/171 transect ghi nhận hiện tượng sạt lở, 29/171 transect ghi nhận quá trình bồi tụ, và 01 transect nào không biến đổi. Hiện tượng sạt lở xảy ra biến thiên từ $-0,31 \mathrm{~m}$ đến $-40,04 \mathrm{~m}$, tốc độ duy trì từ $-0,025 \mathrm{~m} / \mathrm{năm}$ đến $-3,33 \mathrm{~m} / \mathrm{năm}$ với giá trị trung bình 12 năm ước đạt $-0,98$ $\mathrm{m} /$ năm. Quá trình bồi tụ xảy ra biến thiên từ $+0,01 \mathrm{~m}$ đến $+28,28 \mathrm{~m}$, tốc độ duy trì từ +0 đến $+2,36 \mathrm{~m} /$ năm với giá trị trung bình 12 năm ước đạt $+0,99$ m/năm.

Trong giai đoạn 11 năm (2002-2013), có 146/171 transect ghi nhận hiện tượng sạt lở, 21/171 transect ghi nhận quá trình bồi tụ, và 04 transect nào không biến đổi. Hiện tượng sạt lở xảy ra biến thiên từ $-0,24 \mathrm{~m}$ đến $-40,65 \mathrm{~m}$, tốc độ duy trì từ $-0,02$ đến $-3,69 \mathrm{~m} / \mathrm{năm}$ với giá trị trung bình 11 năm ước đạt $-1,31 \mathrm{~m} /$ năm. Quá trình bồi tụ xảy ra biến thiên từ $+0,01 \mathrm{~m}$ đến $+28,76 \mathrm{~m}$, tốc độ duy trì từ +0 đến $+2,61 \mathrm{~m} / \mathrm{năm}$ với giá trị trung bình 11 năm ước đạt $+1,17$ m/năm.

Từ kết quả thống kê biến động đường bờ đoạn sông Pô Kô trong hai giai đoạn, xu hướng sạt lở gia tăng về tốc độ gia tăng (tốc độ sạt lở

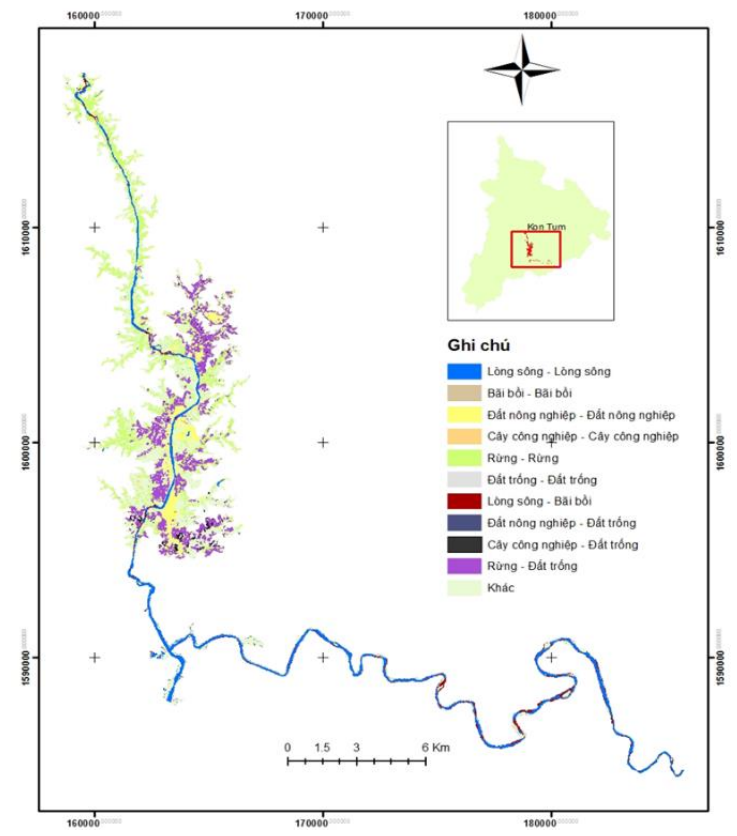

(i) Giai đoạn 1990-2002 trung bình toàn đoạn là $-0,98 \mathrm{~m} /$ năm trong giai đoạn 1990-2002, và -1,31 m/năm trong giai đoạn 2002-2013). Trong khi đó, tốc độ bồi tụ không có chênh lệch nhiều (tốc độ bồi tụ của giai đoạn 1990 - 2002 nằm trong khoảng $[0 ;+2,36]$, giai đoạn 2002-2013 là $[0 ;+2,61])$.

\subsection{Anh hưởng của biến động đường bò̀ khu vưc tới hoạt động sư dụng đất giai đoạn 1990-2013}

Trên cơ sở xác định đường bờ cực đại của khu vực nghiên cứu giai đoạn 1990-2013, nghiên cứu tiến hành xác định biến động diện tích dòng sông cực đại thông qua thuật toán phân loại không kiểm định (K-means algorithms for image classification) cho 06 đối tượng lớp phủ gồm sử dụng đất lòng sông, bãi bồi, đất nông nghiệp, rừng, cây công nghiệp, đất trống. Đây là tiền đề để tiến hành đánh giá ảnh hưởng của quá trình biến động đường bờ tác động lên hoạt động sử dụng đất tại lưu vực sông Sê San. Kết quả đánh giá biến động lớp phủ sử dụng đất trong diện tích lòng sông cực đại giai đoạn 1990-2002 và 20022013 được biểu diễn trong Hình 8 , và thống kê chi tiết trong Bảng 2.

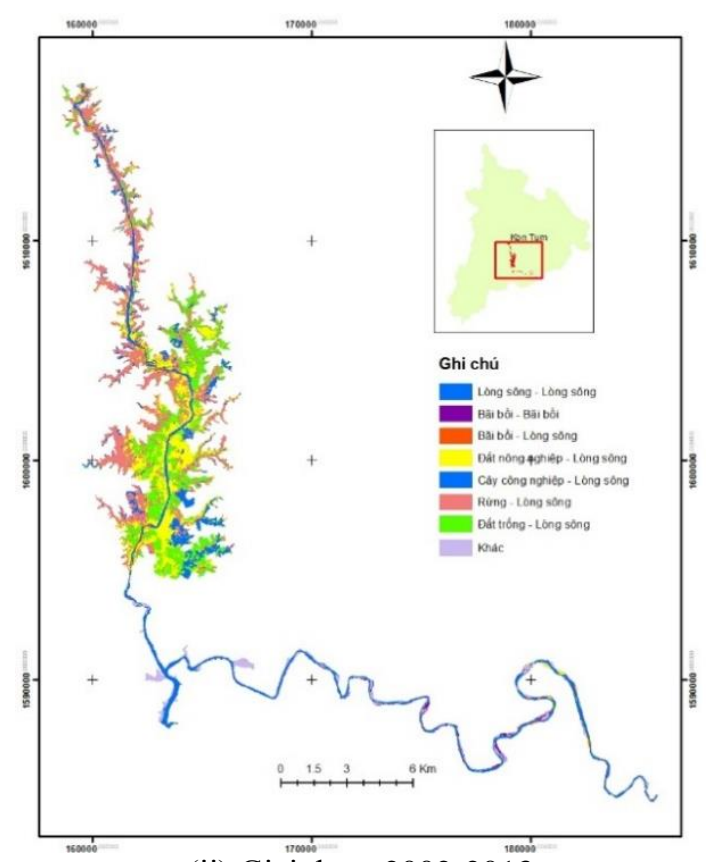

(ii) Giai đoạn 2002-2013

Hình 8. Bản đồ biến động lớp phủ sử dụng đất trong diện tích lòng sông cực đại khu vực nghiên cứu giai đoạn 1990-2013. 
Theo đó, diện tích rừng năm 1990 chiếm diện tích lớn nhất trong khu vực lòng sông cực đại (59\%). Đất nông nghiệp và cây công nghiệp phân bố đều với số lượng không đáng kể (khoảng $9 \%$ ). Đây là thời điểm chưa tiến hành xây dựng các công trình đập thủy điện nên diện tích lòng sông chỉ chiếm $15 \%$ diện tích (882,18 ha). Trong giai đoạn từ 1990-2002, quá trình xây dựng thủy điện Yaly (năm 1993 khởi công) khiến diện tích rừng đầu nguồn và cây lâu năm giảm đi $50 \%$ diện tích so với năm 1990 (chỉ còn chiếm 31\% diện tích). Diện tích đất nông nghiệp gia tăng đáng kể (tăng gấp đôi diện tích), đất trống và đồi núi trọc mở rộng, diện tích lòng sông cũng tăng khoảng $10 \%$ so với năm 1990 . Từ năm 2009 , thủy điện Pleikong đi vào vận hành chính thức, toàn bộ phần diện tích phía trên của vùng nghiên cứu biến thành lòng hồ. Điều này khiến phần lớn diện tích là mặt nước.

Bảng 2. Ma trận thống kê biến đổi lớp phủ sử dụng đất trong diện tích lòng sông cực đại khu vực nghiên cứu giai đoạn 1990-2013

\begin{tabular}{|c|c|c|c|c|c|c|c|}
\hline \multirow{2}{*}{\multicolumn{2}{|c|}{ Ma trận }} & \multicolumn{6}{|c|}{ Diện tích lớp phủ SDĐ năm 2002 (ha) } \\
\hline & & \multirow{2}{*}{$\begin{array}{l}\text { Lòng sông } \\
708,84\end{array}$} & \multirow{2}{*}{$\frac{\text { Bãi bồi }}{139,5}$} & \multirow{2}{*}{ Đât NN } & \multirow{2}{*}{$\frac{\text { Cây CN }}{0}$} & \multirow{2}{*}{$\frac{\text { Rừng }}{0}$} & \multirow{2}{*}{$\begin{array}{c}\text { Đất trống } \\
0\end{array}$} \\
\hline \multirow{6}{*}{ 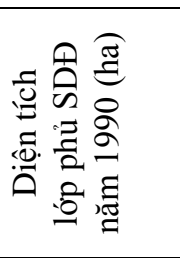 } & Lòng sông & & & & & & \\
\hline & Bãi bồi & 72,81 & 4,95 & 90,54 & 0 & 0 & 64,98 \\
\hline & Đất NN & 64,98 & 0 & 413,91 & 0 & 0 & 43,02 \\
\hline & Cây CN & 0 & 0 & 0 & 465,48 & 7,92 & 40,23 \\
\hline & Rừng & 46,26 & 0 & 535,32 & 447,57 & $1.324,08$ & $1.016,73$ \\
\hline & Đất trống & 24,75 & 0 & 79,11 & 0 & 0 & 71,64 \\
\hline \multirow{2}{*}{\multicolumn{2}{|c|}{ Ma trận }} & \multicolumn{6}{|c|}{ Diện tích lớp phủ SDĐ năm 2013 (ha) } \\
\hline & & Lòng sông & Bãi bồi & Đât NN & Cây CN & Rừng & Đất trống \\
\hline \multirow{6}{*}{ 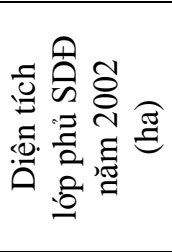 } & Lòng sông & 711,72 & 101,07 & 67,86 & 0 & 0 & 36,99 \\
\hline & Bãi bồi & 75,6 & 50,13 & 16,47 & 0 & 0 & 2,25 \\
\hline & Đất NN & $1.089,18$ & 49,68 & 7,65 & 0 & 0 & 6,21 \\
\hline & Cây CN & 912,96 & 0 & 0 & 0 & 0 & 0,09 \\
\hline & Rừng & $1.327,95$ & 1,17 & 0,27 & 0 & 0 & 2,61 \\
\hline & Đất trống & $1.153,26$ & 0 & 16,38 & 0 & 0 & 66,96 \\
\hline
\end{tabular}

Để kiểm chứng nguyên nhân của tình trạng biến đổi diện tích lớp phủ sử dụng đất trong mối quan hệ với tình trạng xói lở-bồi tụ ở khu vực, nghiên cứu đã tiến hành khảo sát thực địa vào tháng 4 năm 2013 tại 15 điểm trên đoạn sông Đăk Bla và 10 điểm khảo sát trên đoạn sông Pô Kô nhằm kiểm chứng tính tin cậy cậy của cách tiếp cận. Kết quả cho thấy: (i) trên đoạn sông Đăk Bla, nguyên nhân của xu hướng biến đổi đến từ tác động của các đợt mưa, lũ lớn xảy ra hàng năm trên địa bàn khu vực; cũng như tác động của quá trình quy hoạch và khai thác khoáng sản không đúng mức ở khu vực lòng sông. Qua khảo sát thực địa cũng cho thấy, tình trạng khai thác các khoáng sản (sa khoáng, cát, đá, vàng... ) trái phép trên sông Đăk Bla diễn ra trong nhiều năm qua khiến cho nhiều đoạn bờ sông bị sạt lở nghiệm trọng. Một số vị trí lòng sông đã bị khai thác vượt độ sâu cho phép, tạo thành những hố sâu vài chục mét, khi lũ kéo cát về lấp đầy hố làm dòng chảy bị thay đổi; (ii) trên đoạn sông Pô $K o ̂$, do tác động của quá trình xây dựng và vận hành thủy điện Yaly và thủy điện Pleikrong trên địa bàn của tỉnh Kon Tum. Mưa lớn, cộng với việc hồ thủy điện Pleikrong xả lũ không những làm ngập một diện tích lớn khu vực nghiên cứu đồng thời làm bờ sông liên tục bị sạt lở nghiêm trọng. Ngoài ra, quá trình xây dựng thủy điện còn dần tới xu thế chuyển đổi sử dụng đất (từ trồng cây lâu năm sang trồng cây nông nghiệp ngắn ngày hoặc chặt phá rừng lấy gỗ để lại đất trống và đồi núi trọc). Điều này không những làm mất 
đi diện tích rừng đầu nguồn, mà còn khiến các dòng chảy nhanh chóng đổ vào sông khiến mực nước sông dâng cao và gia tăng áp lực lên hai bờ. Kết quả đánh giá hoàn toàn phù hợp với số liệu và hiện trạng biến đổi lớp phủ trên diện tích cực đại lòng sông tại khu vực nghiên cứu. Một số nguyên nhân điển hình được minh họa bằng các ảnh thực địa trong Hình 9.

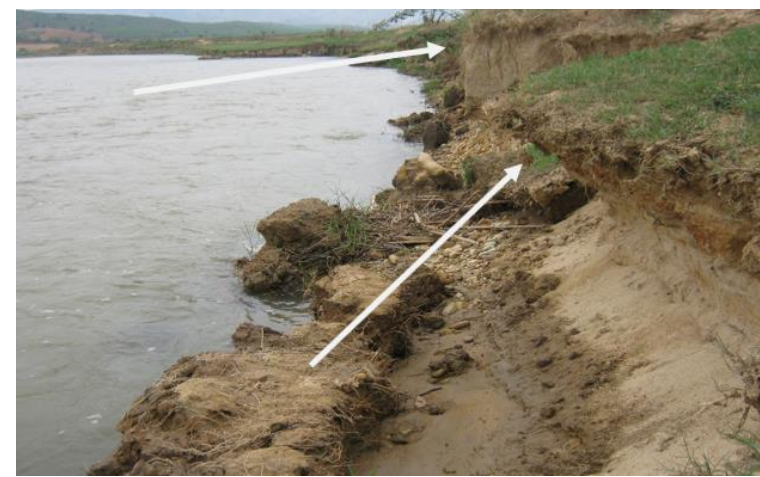

(i) Sạt lở bờ với mức độ mạnh và kéo dài trên sông Đăk Bla (nguồn: ảnh thực địa ngày 12/4/2013).

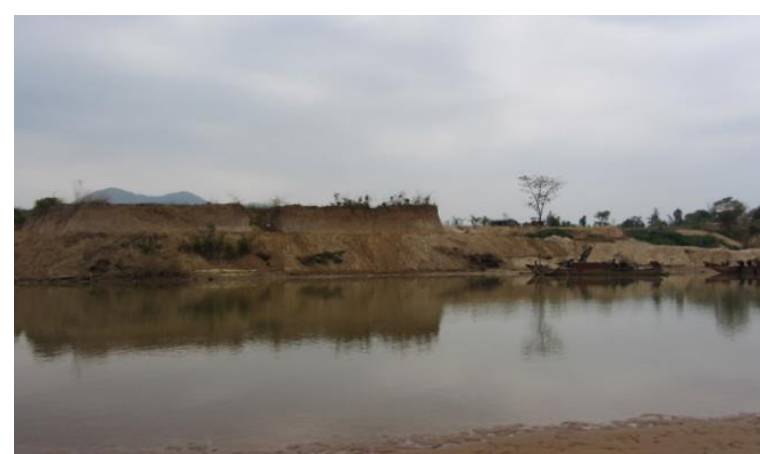

(iii) Khai thác cát trên sông Đăk Bla chảy qua xã Chư Reng (nguồn: ảnh thực địa ngày 10/4/2013).

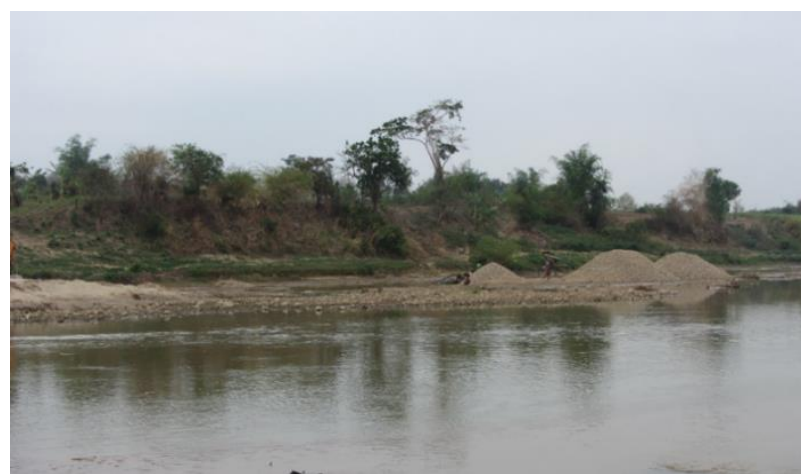

(ii) Khai thác đá, sỏi trên lòng sông Đakbla chảy qua xã Đăk Rơ Wa (nguồn: ảnh thực địa ngày 10/4/2013).

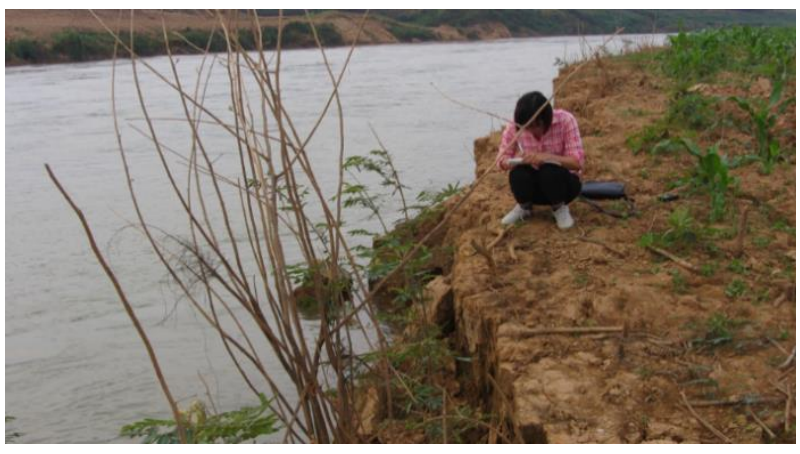

(iv) Sạt lở lớn trên đoạn sông Pô Kô khu vực chảy qua xã Krong (nguồn: ảnh thực địa 15/04/2013).

Hình 9. Một số nguyên nhân điển hình của quá trình biến đổi đường bờ giai đoạn 1990-2013 được xác định thông qua quá trình khảo sát ngoài thực địa.

\section{Kết luận}

Trên cơ sở tiếp cận định lượng của mô hình DSAS trong môi trường GIS, nghiên cứu đánh giá biến đổi đường bờ thông qua dữ liệu viễn thám đa thời gian trở thành một hướng tiếp cận hiệu quả phục vụ giảm thiểu rủi ro và tổ chức lãnh thổ một cách bền vững. Quá trình định lượng mức độ biến động đường bờ NSM và tốc độ biến đổi đường bờ ERP cung cấp cơ sở khoa học cho những đánh giá biến động đối tượng lớp phủ sử dụng đất trên lòng sông cực đại. Kết quả thống kê dữ liệu đối với lưu vực sông Sê San (trên hai chi lưu Đăk Bla và Pô Kô) đã khẳng định ưu thế về tính chính xác, hiệu quả kinh tế và giảm thiểu những khó khăn trong hoạt động quan trắc biến động ngoài thực địa.

Kết quả nghiên cứu biến đổi lòng sông lưu vực thượng lưu sông Sê San cho thấy xu thế tác động ngày càng mạnh lên diện tích sử dụng đất ven bờ giai đoạn 1990-2013 bắt nguồn từ cả nguyên nhân tự nhiên và ảnh hưởng của hoạt động phát triển kinh tế-xã hội tại khu vực. Điề̀u này đã và đang thúc đẩy các tác động tiêu cực tại lãnh thổ ven bờ diễn ra ngày càng mạnh về 
cường độ cũng như tần suất. Và cách tiếp cận này còn mở ra những ứng dụng khác nhau nhằm kế thừa kết quả định lượng không gian của nghiên cứu như dự báo nguy cơ trong tương lai, lượng giá giá trị kinh tế ảnh hưởng bởi quá trình biến đổi đường bờ, phân tích xu thế tiến hóa của cảnh quan, phân tích rủi ro sinh thái,... Do phần diện tích sông cực đại nằm chủ yếu ở khu vực các xã miền núi, với mật độ công trình dân cư thưa thớt, vật liệu xây dựng nhà cửa đa số là thô sơ, đồng thời độ phân giải không gian của dữ liệu ảnh vệ tinh Landsat sử dụng nghiên cứu ở mức trung bình, tính chính xác của nghiên cứu có thể được nâng cao hơn nếu sử dụng ảnh viễn thám đa thời gian có độ phân giải cao hơn.

\section{Lời cảm ơn}

Nghiên cứu này được tài trợ bởi đề tài TN3/T16 và TN3/T20 thuộc chương trình Khoa học và Công nghệ phục vụ phát triển kinh tế - xã hội vùng Tây Nguyên.

\section{Tài liệu tham khảo}

[1] G. García-Rubio, D. Huntley, P. Russell, Evaluating shoreline identification using optical satellite images, Marine Geology 359 (2015) 96106. https://doi.org/10.1016/j.margeo.2014.11.002.

[2] C.B. Boye, K. Appeaning Addo, G. Wiafe, K. Dzigbodi-Adjimah, Spatiotemporal analyses of shoreline change in the Western Region of Ghana, J. Coast. Conserv. Volume 22 Issues 4, 2018, pp. 769-776. http://dx.doi.org/10.1007/s11852-018-0607-z.

[3] S.P. Leatherman, B.C. Douglas, J.L. LaBrecque, Sea level and coastal erosion require large-scale monitoring, EOS Trans. Volume 84 Issues 2, (2003) 13-20. https://doi.org/10.1029/2003EO020001.

[4] G. Eman, M. Jehan, G. Douglass, M. Joanne, A. Mostafa, Nile Delta exhibited a spatial reversal in the rates of shoreline retreat on the Rosetta Promontory comparing pre-and post-beach protection, Geomorphology 228 (2015) 1-14. http://dx.doi.org/10.1016/j.geomorph.2014.08.021

[5] M.R. Muskananfola, Supriharyono, S. Febrianto, Spatio-temporal analysis of shoreline change along the coast of Sayung Demak, Indonesia using
Digital Shoreline Analysis System, Regional Studies in Marine Science 34 (2020) 1-9. https://doi.org/10.1016/j.rsma.2020.101060.

[6] G. Anfuso, D. Bowman, C. Danese, E. Pranzini, Transect based analysis versus area based analysis to quantify shoreline displacement: spatial resolution issues, Environmental Monitoring and Assessment 188 (2016) 568.

https://doi.org/10.1007/s10661-016-5571-1.

[7] D.L. Strayer, S.E.G. Findlay, D. Miller, H.M. Malcom, D.T. Fischer, T. Coote, Biodiversity in Hudson River shore zones: influence of shoreline type and physical structure, Aquatic Sciences 74 (2012) 597-610. https://doi.org/10.1007/s00027012-0252-9.

[8] M. Brabender, M. Weitere, C. Anlanger, M. Brauns, Secondary production and richness of native and non-native macroinvertebrates are driven by human-altered shoreline morphology in a large river, Hydrobiologia 776 (2016) 51-65. https://doi.org/10.1007/s10750-016-2734-6.

[9] Md.S. Newaz, R.W. Mackereth, A.U. Mallik, D. McCormick, How much boreal lake shoreline is burned by wildfire? Implications for emulating natural disturbance in riparian forest management, Forest Ecology and Management 473 (2020) 118-283. https://doi.org/10.1016/j.foreco.2020.118283.

[10] X. Zhang, Z. Yang, Y. Zhang, Y. Ji, H. Wang, K. $\mathrm{Lv}, \mathrm{Z}$. Lu, Spatial and temporal shoreline changes of the southern Yellow River (Huanghe) Delta in 1976-2016, Marine Geology 395 (2018) 188-197. https://doi.org/10.1016/j.margeo.2017.10.006.

[11] B. Yang, C. Hwang, H.K. Cordell, Use of LiDAR shoreline extraction for analyzing revetment rock beach protection: A case study of Jekyll Island State Park, USA, Ocean \& Coastal Management 69 (2012) 1-15. https://doi.org/10.1016/j.ocecoaman.2012.06.007.

[12] J.B. Campbell, R.H. Wynne, Introduction to Remote Sensing, Fifth edition, Guildford Press, 2011, 607 pages.

[13] H. Burningham, J. French, Understanding coastal change using shoreline trend analysis supported by cluster-based segmentation, Geomorphology 282 (2017) 131-149. https://doi.org/10.1016/j.geomorph.2016.12.029.

[14] D.E. Reeve, J. Horrillo-Caraballo, H. Karunarathna, S. Pan, A new perspective on meso-scale shoreline dynamics through data-driven analysis, Geomorphology 341 (2019) 169-191. https://doi.org/10.1016/j.geomorph.2019.04.033.

[15] J. Almonacid-Caballer, E. Sánchez-García, J.E. Pardo-Pascual, A.A. Balaguer-Beser, J. PalomarVázqueza, Evaluation of annual mean shoreline 
position deduced from Landsat imagery as a midterm coastal evolution indicator, Marine Geology 372 (2016) 79-88. https://doi.org/10.1016/j.margeo.2015.12.015.

[16] E. Sánchez-Garcíaa, J.M. Palomar-Vázquez, J.E. Pardo-Pascual, J. Almonacid-Caballer, C. Cabezas-Rabadán, L. Gómez-Pujol, An efficient protocol for accurate and massive shoreline definition from mid-resolution satellite imagery, Coastal Engineering $160 \quad$ (2020) 103732. https://doi.org/10.1016/j.coastaleng.2020.103732.

[17] J.E. Pardo-Pascual, J. Almonacid-Caballer, L.A. Ruiz, J. Palomar-Vázquez, Automatic extraction of shorelines from Landsat TM and ETM+ multitemporal images with subpixel precision Remote Sensing of Environment 123 (2012) 1-11. https://doi.org/10.1016/j.rse.2012.02.024.

[18] R. Aedla, G.S. Dwarakish, D.V. Reddy, Automatic Shoreline Detection and Change Detection Analysis of NetravatiGurpurRivermouth Using Histogram Equalization and Adaptive Thresholding Techniques, Aquatic Procedia 4 (2015) 563-570. https://doi.org/10.1016/j.aqpro.2015.02.073.

[19] Md.A. Kabir, Md. Salauddin, K.T. Hossain, I.A. Tanim, Md.M.H. Saddam, A.U. Ahmad, Assessing the shoreline dynamics of Hatiya Island of Meghna estuary in Bangladesh using multiband satellite imageries and hydro-meteorological data. Regional Studies in Marine Science 35 (2020) 101167. https://doi.org/10.1016/j.rsma.2020.101167.

[20] J. Moussaid, A.A. Fora, B. Zourarah, M. Maanan, M. Maanan, Using automatic computation to analyze the rate of shoreline change on the Kenitra coast, Morocco, Ocean Engineering 102 (2015) pp. 71-77.

https://doi.org/10.1016/j.oceaneng.2015.04.044.

[21] E.H. Boak, I.L. Turner, Shoreline Definition and Detection: A Review, Journal of Coastal Research 214 (2005) 688-703. https://doi.org/10.2112/03-0071.1.

[22] N.Q. Tuan, H.C. Tin, L.Q. Doc, T.A. Tuan, Historical Monitoring of Shoreline Changes in the Cua Dai Estuary, Central Vietnam Using MultiTemporal Remote Sensing Data, Geosciences 7 (3) (2017) 72. https://doi.org/10.3390/geoscien ces7030072.

[23] T.H. Phuong, H.P. Phung, N.T. Hung, H.C. Tri, Assessing the shoreline changes in Tra Vinh province using multi-temporal remote sensing data, Vietnam Journal of Science and Technology 56 (5) (2018) 612-624. https://doi.org/10.15625/2525-2518/56/5/10944.

[24] N. Raj, B. Gurugnanam, V. Sudhakar, P.G. Francis, Estuarine shoreline change analysis along The Ennore river mouth, south east coast of India, using digital shoreline analysis system, Geodesy and Geodynamics 10, Issue 3 (2019) 205-212. https://doi.org/10.1016/j.geog.2019.04. 002.

[25] J.T. Kelly, S. McSweeney, J. Shulmeister, A.M. Gontz, Bimodal climate control of shoreline change influenced by Interdecadal Pacific Oscillation variability along the Cooloola Sand Mass, Queensland, Australia, Marine Geology 415 (2019) 105971. https://doi.org/10.1016/j.margeo.2019.105971.

[26] R.R. Goforth, S.M. Carman, Multiscale Relationships between Great Lakes Nearshore Fish Communities and Anthropogenic Shoreline Factors, Journal of Great Lakes Research 35 (2) (2009) 215-223. https://doi.org/10.1016/j.jglr.2009.02.001.

[27] S. Buckman, M.A. de Alarcon, J. Maigret, Tracing shoreline flooding: Using visualization approaches to inform resilience planning for small Great Lakes communities, Applied Geography 113 (2019) 102097. https://doi.org/10.1016/j.apgeog.2019.102097.

[28] W.G. Rees, Physical Principles of Remote Sensing, Third edition, Cambridge University Press, 2013, 492 pages.

[29] G. Winasor, S. Budhiman, The Potential Application of Remote Sensing Data for Coastal Study, Proc. 22nd Asian Conference on Remote Sensing, Singapore, 2001.

http://www.crisp.nus.edu.sg/ acrs2001/pdf/084 Winar.pdf.

[30] J. B. MacQueen, Some Methods for classification and Analysis of Multivariate Observations, Proceedings of 5th Berkeley Symposium on Mathematical Statistics and Probability, Berkeley, University of California Press, 1967, pp. 281-297.

https://projecteuclid.org/download/pdf_1/euclid. bsmsp/1200512992.

[31] E.R. Thieler, E.A. Himmelstoss, J.L. Zichichi, A. Ergul, The Digital Shoreline Analysis System (DSAS) Version 4.0-an ArcGIS Extension for Calculating Shoreline Change, US Geological Survey Open-File Report, 2009.

https://cmgds.marine.usgs.gov/publications/DSA S/of2008-1278. 